\title{
periferio
}

\section{CONCEPÇÃO DE EDUCAÇÃO DE SURDOS NAS TESES E DISSERTAÇÕES EM PESQUISAS EM EDUCAÇÃO}

\author{
Eleny Brandão Cavalcante 1 \\ Universidade Federal do Oeste do Pará
}

\section{Resumo}

Este artigo é um recorte de minha tese de doutorado e busca analisar os dados empíricos correspondentes a 31 teses e dissertações (das quais 5 teses e 26 dissertações) que indicaram em seus resumos trabalharem com Marx, Vigotski e/ou com a teoria histórico-cultural, analisando a concepções de educação de surdos. A escolha desses critérios foi por serem referenciais marxistas. Essas pesquisas foram alcançadas a partir de um levantamento documental no banco de dados dos Programas de Pós-graduação em Educação reconhecidos pela CAPES, no tema da educação de surdos. Procuro demonstrar como as teses e dissertações concebem a educação de surdos. Como resultado indico um apanhado teórico de como a educação de surdos tem sido concebida nestas produções, no aspecto educacional.

Palavras-chave: educação de surdos; Vigotski; teoria histórico-cultural

1 Doutora em Educação pela Universidade Estadual de Campinas. Professora Adjunta da Universidade Federal do Oeste do Pará, Santarém -PA. elenycavalcante@hotmail.com 


\title{
periferio
}

\section{CONCEPTION OF EDUCATION OF DEAF IN THESES AND DISSERTATIONS IN RESEARCH IN EDUCATION}

\begin{abstract}
This is article is a cut from my doctoral thesis and seeks to analyze the empirical data corresponding to 31 theses and dissertations (of which 5 theses and 26 dissertations) that indicated in their summaries work with Marx, Vigotski and / or historical-cultural theory, Analyzing conceptions of deaf education. The choice of these criteria was because they were Marxist references. These researches were obtained from a documentary survey in the database of Postgraduate Education Programs recognized by CAPES, in the topic of education of the deaf. I try to demonstrate how theses and dissertations conceive the education of the deaf. As a result I indicate a theoretical view of how the education of the deaf has been conceived in these productions, in the educational aspect.
\end{abstract}

Keywords: deaf education; Vigotski; historical-cultural theory 


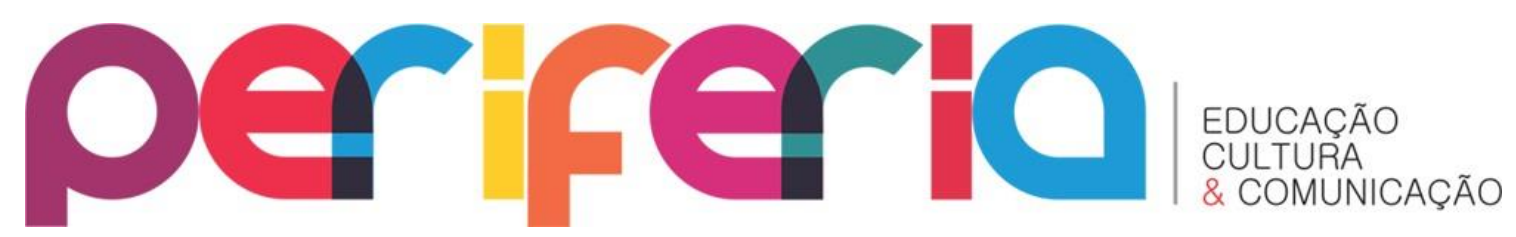

\section{A CONCEPÇÃO DE EDUCAÇÃO DE SURDOS}

As pesquisas analisadas nesse artigo, foram analisadas na minha pesquisa de doutorado intitulada "Educação de surdos: um estudo das teses e dissertações de 1990 a 2013". Nesse artigo faço um recorte e analiso as que trabalharam com os referenciais de Marx, Vigotski e/ou a teoria históricocultural, a fim de compreender a analisa de pesquisas que sustentavam-se em referenciais marxistas.

Todas as teses e dissertações analisadas têm uma visão de educação de surdos, que está pautada, fundamentalmente, no reconhecimento e valorização da língua de sinais, como língua dos surdos e como meio necessário para que a educação desses sujeitos possa ser viabilizada.

Os autores mais citados nas pesquisas foram indicados na tabela por trabalho, e os que apresentaram maior incidência nas produções, somando as produções de obras próprias ou em coautoria, foram os seguintes teóricos: Lacerda (36); Quadros (29); Góes (25); Skliar (20); Lodi (15); Souza (14); Botelho (13); Perlin (13); Goldfeld (13); Fernandes (12); Sacks (12) e Moura (11). Esses autores discutem a educação de surdos a partir de temáticas como: história da educação de surdos; concepções de educação de surdos; Língua de Sinais; Linguística da Língua de Sinais; Aquisição da linguagem; Bilinguismo; Intérprete de Libras; modelo socioantropológico. As autoras bastante citadas no campo da teoria histórico-cultural foram: Lacerda e Góes.

0 debate das pesquisas de teses e dissertações, acerca da educação de surdos ficou muito mais vinculado às diferentes concepções de educação de surdos, quais sejam: oralismo, comunicação total e bilinguismo. Além disso, problematizam também o local mais adequado para a educação de surdos: 1) ensino regular; 2) escola especial e 3) escola para surdos. Além do local mais adequado para a educação, a discussão sobre quem seria a pessoa "mais adequada" (surdo ou ouvinte) para ministrar a disciplina de Libras também é abordada nas pesquisas. A concepção teórica predominante nos trabalhos é o bilinguismo, tendo em vista que todos os trabalhos reconhecem o status 


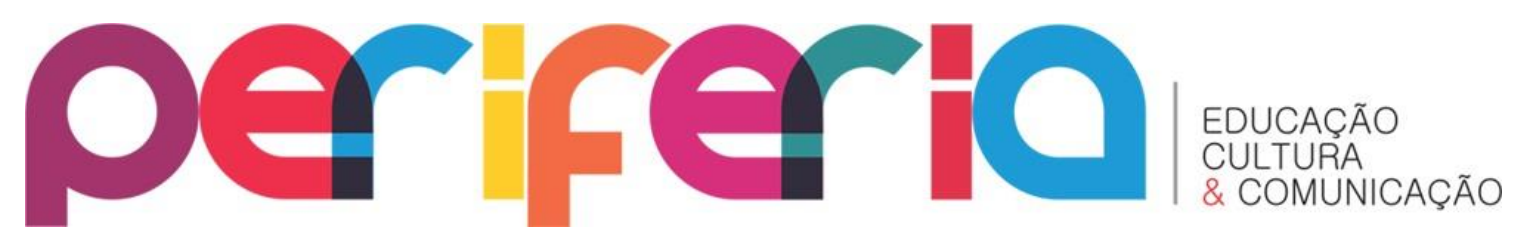

linguístico da língua de sinais, garantido na Lei $\mathrm{n}^{\circ} 10.436 / 02$ e regulamentada pelo Decreto ${ }^{\circ} 5626 / 05$.

Sobre a primeira concepção teórica, o oralismo, as pesquisas criticam veementemente essa visão, que sustenta a educação de surdos no modelo médico. Essa concepção percebe a surdez como patologia, deficiência, centrando as intervenções e até mesmo a prática no ambiente escolar, na reabilitação, por meio de treinos auditivos, implantação de aparelhos, implantes e treinamentos fono-articulatórios.

As pesquisas fazem uma análise dessa concepção pautada no dualismo surdo $\mathrm{x}$ ouvinte, pois atribuem as imposições de reabilitação, castigos e a proibição da língua de sinais, a uma "comunidade ouvinte" cruel e sectária, que quer que o surdo seja "normalizado" para ser aceito e ter sua deficiência camuflada aos olhos da sociedade. Essa prática de entendida como "opressão" é chamada de "ouvintismo".

O ouvintismo seria, assim, a prática do oralismo e uma prática de poder, na qual o surdo é subjugado pelos ouvintes, que querem normatizá-lo. A concepção oralista é, segundo as pesquisas, vigente até os nossos dias, permeando às políticas de educação de surdos, mesmo tendo ocorrido alguns progressos, fomentados, principalmente, pela mobilização dos próprios surdos. O oralismo passa a ser a concepção que permeia a visão acerca do surdo. Soares (1999) conceitua o oralismo da seguinte forma:

Oralismo, ou método oral, é o processo pelo qual se pretende capacitar o surdo na compreensão e na produção de linguagem oral e que parte do princípio de que o indivíduo surdo, mesmo não possuindo o nível de audição para receber os sons da fala, pode se constituir em interlocutor por meio da linguagem oral. (SOARES, 1999, p. 1).

Muitos dos trabalhos iniciam a discussão sobre a educação de surdos a partir desse congresso, tendo em vista sua forte influência sobre as questões educacionais dos surdos, cujas consequências são indicadas como nefastas para esses sujeitos. Grupos mais radicais sustentam-se nos malefícios 


\section{periferio}

decorridos desses longos anos de vigência do oralismo, como argumento para suas propostas educacionais de educação para surdos, alicerçados em conceitos como: identidade, cultura, alteridade, comunidade, povo, língua natural etc.

O fracasso da prática dessa concepção é fortemente criticado e atribuise ao oralismo, muitos problemas provenientes dela, como a questão da baixa autoestima e a disseminação da visão social de que o surdo é "incapaz" e "inferior". A visão de incapacidade é atribuída como agente propulsor que contribuiu para a proliferação de uma visão excludente e de discursos e práticas denominadas de "ouvintistas".

0 oralismo é bastante criticado e suas consequências são tomadas como a justificativa do fracasso educacional e da não inserção social do surdo ao longo dos anos. Apesar de nenhuma pesquisa analisada indicar ser sustentada nessa concepção, ela é resgatada e criticada, com base nos argumentos brevemente apontados, como uma visão médica, ou clínicoterapêutica da surdez, sempre sustentada na opressão dos ouvintes em relação aos surdos, marcando o que é indicado como relações de poder.

Uma das pesquisas (COD94) classifica-se como adotando um conceito médico da surdez, indicando em seu texto a classificação da surdez, o grau da surdez, por outro lado, valoriza a importância da língua de sinais e da aquisição da língua escrita por parte do surdo. Sustenta sua concepção tomando como base o debate de Bueno (1998), que destaca não ser a surdez o fator único determinante do indivíduo surdo. Segundo essa pesquisa:

É dentro desta ótica que este trabalho parte do conceito médico da surdez e da marca social que esta deficiência representa em decorrência do tempo e espaço, que tem o uso da linguagem como lugar de construção de recursos linguísticos, meio de interação social e acesso à cultura; com base nessas premissas, compreendemos a relevância do aprendizado da escrita; sendo assim, conhecer e aprofundar o conceito de alfabetização e letramento, bem como o processo de aprendizado da escrita, foi imprescindível para avançarmos na discussão específica da educação dos surdos. (COD94, 2011, p. 45). (grifo meu). 


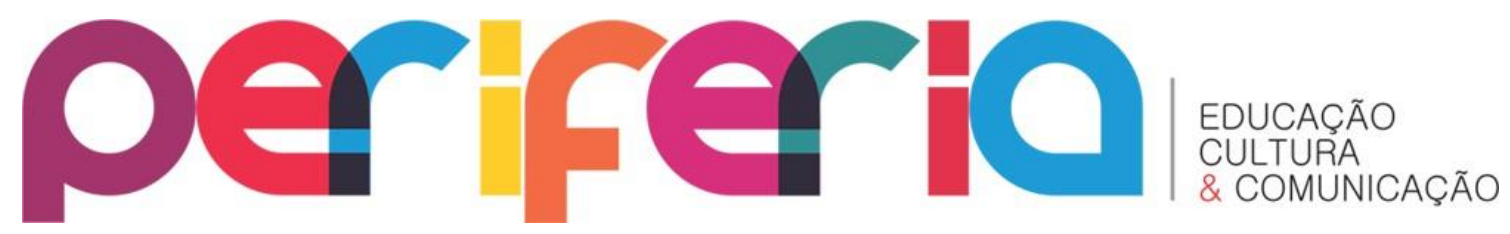

A pesquisa não considera a surdez como comumente é admitida, ou seja, como uma diferença, mas ao contrário como uma condição real de privação de audição, por isso, talvez ela a considere como pautada no modelo médico. A autora na pesquisa problematiza a dualidade surdo $\mathrm{x}$ ouvinte $\mathrm{e} a$ forma restrita com que se tem analisado a história e o fracasso escolar do surdo. Segundo a pesquisa, a concepção de Bueno (2001) viria se contrapor ao modelo pautado no multiculturalismo, que segundo ela:

Em contraposição, Bueno (2001) destaca que não podemos separar os baixos resultados alcançados pela população surda de outros grupos, tanto os que apresentam alguma deficiência, como física, mental, ou visual, quanto os não deficientes, representantes de grupos sociais pauperizados, como os meninos de rua, os negros, etc. 0 fracasso escolar dos surdos reflete, segundo o autor, não um processo de dominação dos ouvintes sobre os que não ouvem, mas de grupos dominantes, tanto do ponto de vista econômico, quanto do social e cultural, sobre as camadas desprivilegiadas da população. (COD94, 2011, p.2).

A pesquisa, sustentada em Bueno (2001), aponta para a necessidade de relacionar ao fator biológico "surdez" os outros fatores determinantes, como a questão econômica, social, de gênero, raça. Faz afirmação que deixa em dúvida a condição linguística da língua de sinais:

Constatamos, nesta escola, e especificamente nesta turma, evidenciando com a descrição dos sujeitos, que não se tratava de uma sala homogênea, ou seja, a professora lidava com um universo variado, composto por alunos que demonstravam ouvir; alguns se comunicavam pela língua de sinais e outros por fala e língua de sinais, o que parecia não corresponder à corrente teórica denominada socioantropológica, para a qual a Libras é a primeira língua dos surdos, sendo esta expressão de uma cultura, comunidade e identidade surdas.

Tal constatação nos faz refletir se a língua de sinais não seria somente o meio de comunicação desenvolvido por surdos que, por algum impedimento ou dificuldade, não foram oralizados, ou seja, de que a comunicação por meio da Libras seria decorrente da impossibilidade de aquisição de uma língua oral. (COD94, 2011, p. 109-110). (grifo meu) 


\section{periferio}

A autora critica a concepção socioantropológica e a afirmação, comumente feita nesse campo de debate, de ser a língua de sinais a primeira língua dos surdos. E afirma ser a língua de sinais um meio desenvolvido pelos surdos para se comunicar, na ausência da audição. Concordo com a autora com a afirmação de que a língua de sinais emerge a partir da condição de não acesso à língua oral, na qual o surdo por meio de sua capacidade de desenvolver a língua e pela necessidade de comunicação, desenvolveu a língua de sinais. Esse fator, não diminui o caráter de língua e nem a deixa em uma condição inferior e nem diferente da criação de toda e qualquer língua. Sobre a teoria socioantropológica, concordo com a autora de que é uma visão que tem sido difundida sem uma análise mais detida de suas matrizes fundantes. Analisarei mais adiante essa questão.

Retomo as concepções de educação de surdos presentes nas teses e dissertações. A concepção da comunicação total (doravante CT) é resgatada em algumas das pesquisas analisadas, no entanto, não tem tanta centralidade no debate quanto o oralismo. Indicarei o que trata tal visão e o que os autores que discutem tal temática apontam.

O termo “comunicação total” foi criado por Roy Holcomb (1923-1998) consistindo na utilização de diferentes formas de comunicação com a criança surda, visando o estabelecimento de comunicação. Na Conferência das Escolas Americanas para surdos de 1976, a comunicação total foi oficializada como mais adequada para assegurar a comunicação dos surdos. (MOURA, 2000).

A comunicação total objetiva estabelecer a comunicação com a pessoa surda eliminando toda e qualquer barreira para a efetivação da mesma, a fim de transmitir conceitos, informações, vocábulos e ideias, lançando mão para isso de "sinais, leitura labial, amplificação e alfabeto digital, para fornecer input linguístico para estudantes surdos" (SILVA, 2008, p. 23).

Essa comunicação permite o uso da língua de sinais, destacando o seu uso simultâneo com a língua oral o que, entretanto, é difícil de ser realizado, devido às diferenças de modalidades. A língua de sinais utiliza o visuoespacial, 


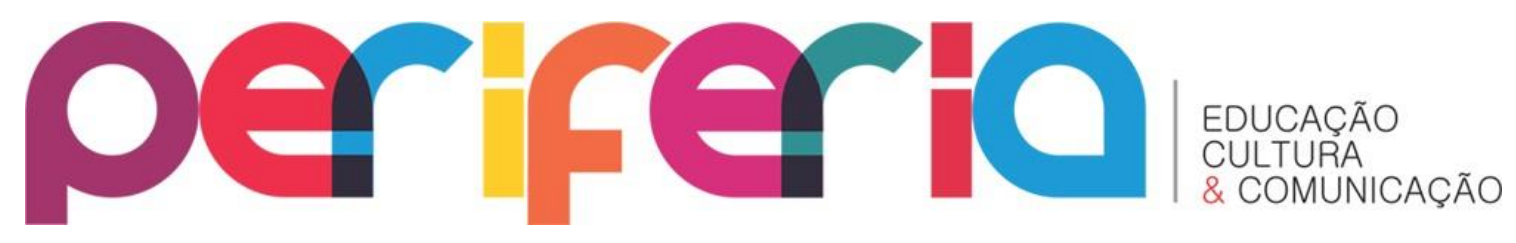

enquanto que as línguas orais utilizam o canal oral auditivo, sendo difícil de serem utilizadas ao mesmo tempo, por suas especificidades estruturais e gramaticais próprias.

A comunicação total expandiu-se nos Estados Unidos a partir da Conferencia das Escolas Americanas em 1976, que instituía a CT como modelo mais adequado à educação dos surdos, influenciando outros países. Inicialmente a CT não especificava uma técnica de comunicação que fosse percebida como a melhor forma de se comunicar com a criança surda, mas utilizava várias simultaneamente, inclusive os sinais. Posteriormente, a língua de sinais foi abandonada prevalecendo outros métodos, sem a devida atenção a especificidade linguística da criança surda.

A comunicação total também é denominada como Comunicação Bimodal, que seria a comunicação simultânea que utiliza paralelamente combinações de duas modalidades diferentes de língua para estabelecer a comunicação. Essa prática, por mais habilidade que tenha o "falante" sempre irá sobrepor a estrutura de uma das línguas em relação à outra. (SILVA, 2008).

Como contraponto tanto ao oralismo quanto à comunicação total, é indicada na literatura e nos trabalhos o bilinguismo, adotado pela totalidade dos trabalhos, direta ou indiretamente. Essa adesão pode ser proveniente da indicação dessa concepção de educação, no Decreto $n^{\circ}$ 5626/05, como educação a partir da qual deve ser pensada a prática com os sujeitos surdos.

Os argumentos de muitos dos trabalhos em busca de uma nova concepção para a educação de surdos são provenientes de mudança de olhar para com esse sujeito surdo, motivada pela própria luta dos mesmos. Destaco os trabalhos que indicam as críticas ao modelo ouvintista. 0 excerto que indico abaixo mostra que há uma visão ouvinte, opressora e equivocada, contrapondo-se com uma visão surda, libertadora e condizente com a educação de surdos:

Percebemos algumas diferenças marcantes entre estas duas perspectivas. A análise trazida pelos Movimentos Surdos 


\section{periferio}

explicita claramente a vinculação da história às formas organizativas desenvolvidas por estes grupos como forma de resistência às imposições a que eram submetidos nos diversos momentos históricos - a história dos surdos é a história das Associações e dos Movimentos Surdos. Seus ícones são líderes e professores surdos e alguns ouvintes que colaboraram com sua emancipação. Deixa muito claro, também, que não se constituíram "deficientes" por si próprios, mas em íntima e fundamental relação com aqueles que os julgavam seres inferiores. Consideram-se diferentes em todos os momentos históricos e submeteram-se, não sem resistir, aos mandos e desmandos das teorias e ideais de todas as épocas.

A perspectiva dos ouvintes, por outro lado, enfatiza a criação de escolas, os métodos pedagógicos, as disputas linguísticas, os avanços tecnológicos em direção à cura. Seus ícones são os grandes médicos, educadores e cientistas ouvintes e raras são as referências a educadores e líderes surdos. Entretanto, podemos observar alterações significativas nas suas narrativas históricas a partir das diferentes concepções que abraçam, sendo que a maioria dos estudos atuais já traz uma abordagem mais condizente com as Teorias Críticas e Pós-Críticas do que com abordagens de cunho biológico. Vemos, então, que a concepção clínicoterapêutica vem perdendo terreno para a concepção antropológico-cultural. (COD254, 2003, p.57).

Essa citação é mencionada para indicar a visão de história, como dependente do narrador, indicando que os surdos teriam mais "propriedade" para "narrar" sua história do que os ouvintes. Nessa visão, como na grande maioria dos trabalhos pesquisados, a história é desvinculada de seu contexto político, econômico e cultural, sendo indicada por fatos e personagens que tem seus feitos exaltados ou criticados ao longo dos anos, indicando uma cronologia crescente que vai agregando conquistas de direitos, provenientes das lutas dos grupos de pessoas surdas.

Sobre a abordagem da história nos trabalhos sobre surdez, Bueno (1998) é bem enfático quando afirma que a dualidade surdos $x$ ouvintes, já destacada, prevalece nas explicações do fracasso dos surdos, assim como é pautada em uma visão presentista que busca explicar o presente pelo passado, sem vinculação com seu aporte material determinante. Sobre essa questão o autor afirma: 


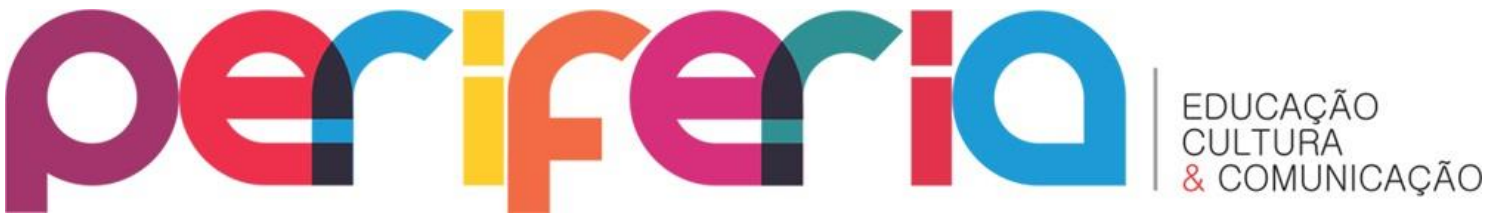

A primeira consideração a ser feita é de que a recuperação histórica realizada por estes autores procura explicar o presente pela trajetória passada. Em outros termos, o que justifica o fato do surdo não ter um lugar ao sol foi imposição feita pelos ouvintes para a incorporação de uma língua que não é sua.

Por outro lado, para estes mesmos autores, a sucessão dos fatos históricos é uma constante progressão, do menos adequado ao cada vez mais adequado, ou seja, desde a imposição da língua oral e de sua progressiva e adequada substituição pelo Sinal.

Esta concepção "presentista e progressista" produz uma história justificadora da realidade atual, na medida em que coloca o presente como consequência inexorável do suceder dos fatos históricos. Assim é que esta visão parte do princípio de que, tendo em vista a desvalorização que se deu no suceder da história, sobre a importância do Sinal, só poderíamos desembocar na situação atual, onde apenas alguns conseguem enxergar toda a riqueza e propriedade com relação à "comunidade surda". (BUENO, 1998, p. 8-9).

Como foi indicado na citação, a história abordada nos trabalhos tem seguido uma linearidade, criando personagens e fatos que rumam para uma ascensão contínua em direção ao reconhecimento da língua de sinais. Os conflitos e contradições históricas, assim como seus determinantes políticos, sociais, econômicos, culturais são apagados em nome de uma visão abstrata dos ouvintes em relação aos surdos.

Assim, os trabalhos ao invés de buscar uma aproximação da realidade através de explicações que visem compreender a realidade da educação e da história do surdo, inseridas na realidade social, econômica e de classes concretas, que a determinam, dedicam-se em explicações idealistas, na qual justificam a exclusão do surdo, como motivada pela “criação” dos ouvintes de uma surdez pautada na patologia.

Sobre as concepções de ciência da história, Adam Schaff em seu livro "História e Verdade" indica que existem duas concepções sobre história: o positivismo e o presentismo. No primeiro, a história seria o reflexo do fator objetivo, no segundo, seria a negação da possibilidade do conhecimento e a história como explicável pelos interesses presentes, o que caracteriza o 


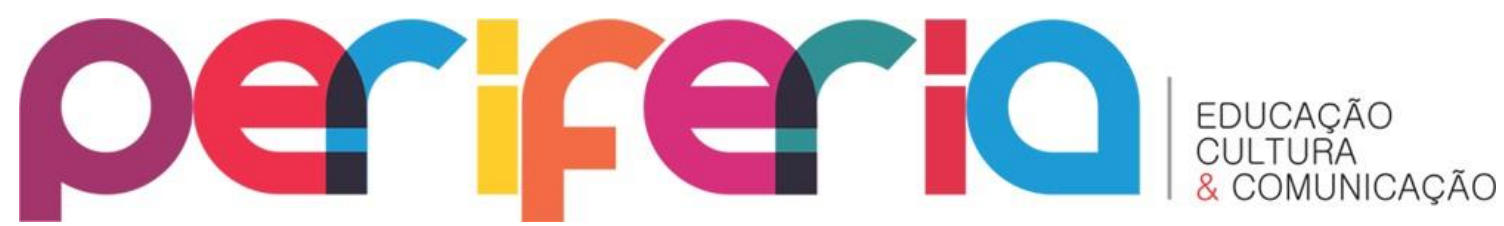

“relativismo subjetivista”. As pesquisas aqui analisadas em sua grande maioria caracterizam-se pela segunda concepção de história. Schaff (1995) explica:

Segundo Croce, a intuição pura é a forma fundamental da atividade do espírito: fundamental porque é independente da atividade prática, enquanto que a atividade prática, pelo contrário, depende da intuição. A intuição é o fundamento da existência porque cria o seu objeto. Este objeto são os "estados da alma" fora dos quais nada existe. O intuicionismo de Croce conduz a sua "filosofia do espírito" ao exagero, porque elimina tudo o que é exterior ao psiquismo individual e cria uma filosofia do "imanentismo absoluto". Desde logo se compreende porque Croce critica Vico e Hegel por terem introduzido na filosofia o transcensus metafísico e obscurecido, assim, o fato de que o homem possui apenas a sua experiência imanente, que existe apenas na realidade - 0 "Espírito" que é atividade, liberdade e "criador eterno da vida". (SCHAFF, 1995, p. 108).

Schaff (1995) afirma que Croce (1866-1952), além do intuicionismo, desenvolve em sua "filosofia do espírito", a teoria do presentismo, que explica a história a partir do presente, indica que todos os fatos são históricos, na medida em que são pensados, negando a existência de fatos fora do pensamento. Para Croce, os fatos são crônicas de verdade pautadas na experiência interior, marcando sua visão subjetivista. Schaff (1995) afirma:

É esta visão radicalmente subjetivista da história que o presentismo subentende. Porque se tudo o que existe é um produto do espírito, os fatos históricos são-no igualmente. Não há passado objetivamente dado, há apenas fatos criados pelo espírito num presente eternamente variável. Toda a história deve pois ser atual, visto que é o produto de um espírito cuja atividade se situa sempre no presente, e que cria a sua imagem histórica (fora da qual não existe história) sob a influência de interesses e de motivos atuais. (SCHAFF, 1995, p. 111).

Afirma ainda:

Segundo Croce, cada ato espiritual (ora, na sua opinião, a história é um deles) contém todo o passado e, vice-versa, o passado ressuscita apenas no momento em que os documentos 


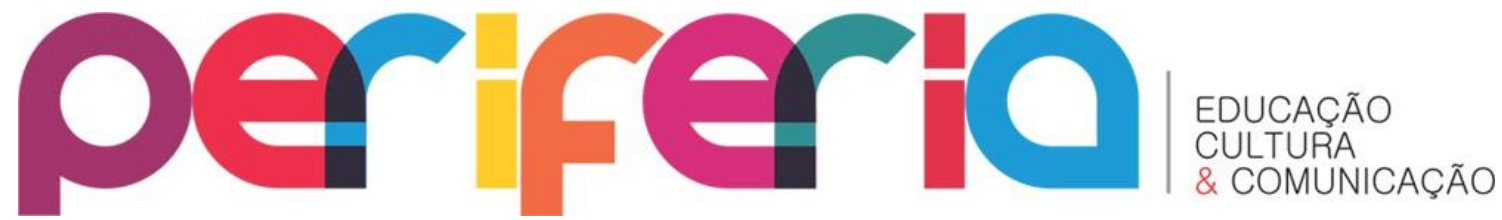

evocam e fixam as recordações de estados espirituais definidos (que evidentemente não se podem manifestar senão no presente, atualmente). $\mathrm{Na}$ ausência desta atividade espiritual, os documentos (monumentos, crônicas, buscas arqueológicas, etc) são apenas objetos mortos. Daí resulta que não pode falar-se de história senão na condição de experimentar pessoalmente certos estados e sentimentos (por exemplo, a caridade cristã, a honra cavalheiresca, o radicalismo dos Jacobinos, etc); desta maneira, a história constitui uma projeção particular do “eu”, projeção criada por necessidades atuais e tornadas possível graças ao fato de que "o homem é um microcosmo... no sentido histórico, uma síntese da história do mundo". Toda história é constituída saindo ao mesmo tempo do presente e da experiência interior. (SCHAFF, 1995, p. 111-112).

A pesquisa destacada indica a compreensão de história como dependente do presente e do sujeito, do “espírito" que a faz emergir a partir do presente, fazendo com que as fontes sejam dependentes nessa análise idealista do "eu" projetado nas coisas. A compreensão de história particular subjetiva pode ser frequentemente percebida nos trabalhos analisados. 0 exemplo mais elucidativo é do trabalho abaixo, quando indica que a história do surdo, contata por um surdo, seria mais verdadeira do que a contada por um ouvinte:

0 interessante nestes trabalhos é a possibilidade de nós, ouvintes, observarmos como estes sujeitos se vêem no processo educacional e social que foram determinados para eles. As suas interpretações dos fatos históricos são muito diferentes das que encontramos nos estudos realizados por ouvintes. É muito comum encontrarmos referências, por exemplo, ao imperialismo ouvinte, à dominação oralista e ao sofrimento dos surdos. A expressão sofrimento do surdo é uma das mais frequentes nos relatos destas pessoas sobre sua educação, sobre suas relações familiares, sobre seu trabalho e suas vidas em geral. (COD254, 2003, p. 30). (grifos do autor)

A pesquisa indica uma característica bastante presente na abordagem da história dos trabalhos analisados, que se sustentam na explicação do fracasso do surdo como proveniente da “opressão dos ouvintes”. Essa análise, como uma visão sustentada no presentismo exposto por Schaff (1995), busca 


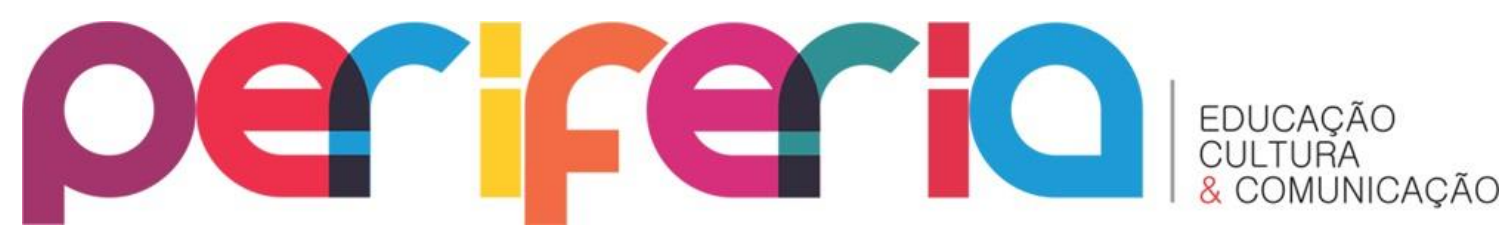

justificar o presente como consequência do passado e exacerba a centralidade do sujeito, marcando sua característica de subjetividade e relativismo.

Sobre o radicalismo dessa visão subjetiva contida no presentismo, Schaff (1995) afirma:

A interpretação radical do presentismo, como está implícito em Croce, leva a consequências muito graves; particularmente a reconhecer-se que não pode falar-se de história, porque existe uma multiplicidade de histórias - igual à quantidade de espíritos que "criam" a história. Por conseguinte, é preciso admitir que não só cada época possui a sua imagem particular da história, como cada nação, cada classe social, mas também, praticamente, cada historiador e mesmo cada indivíduo pensante. É preciso igualmente aceitar que o único critério permitido julgar estas histórias múltiplas e necessariamente diferentes, a medida na qual elas correspondem às necessidades, aos interesses, às exigências... De quem? A resposta a esta pergunta só se justifica se reconhecendo o indivíduo como "medida de todas as coisas". (SCHAFF, 1995, p. 113-114).

Sustentados nessa visão, os trabalhos indicam que a história verdadeira seria aquela contada pelos surdos, pois eles têm a vivencia do que é ser surdo. Ou seja, apenas o surdo teria a autoridade para falar de sua história. Percebe-se aí um forte idealismo e uma visão de história que não busca os fatos para a compreensão da realidade, mas as diferentes narrativas sobre as histórias individuais.

Outro aspecto bastante presente na concepção de educação de surdos nos trabalhos analisados é a incessante busca de classificação da surdez com o debate sobre às diferenças, minorias linguísticas, sempre pautado no confronto surdo $\mathrm{x}$ ouvinte, como principal argumento das análises.

A concepção de educação de surdos é pautada na diferença, na busca de combater uma dominação do oralismo e de práticas sustentadas no ouvintismo. Os surdos são instigados a falar sobre si, sua história, sua língua, na tentativa de legitimação de uma cultura e de sua especificidade linguística. 


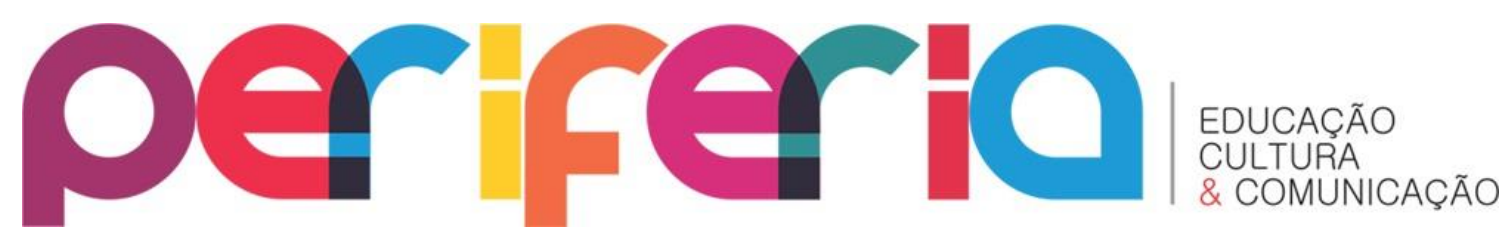

0 argumento principal para a mudança de concepção é o deslocamento da visão sobre a surdez, que deve mudar de um modelo pautado na deficiência para um modelo sustentado na diferença. Esse grupo de trabalhos classifica o surdo como pertencente a uma minoria linguística. Alguns trabalhos indicam essa visão:

Focalizando a educação da pessoa surda Behares (1995) propõe que a surdez seja vista como um "déficit de audição que apresenta diferença com relação ao modelo esperado" e não mais como patologia. 0 surdo que utiliza Libras, segundo o autor, deve ser visto como pertencente a uma minoria linguística e cultural, que se utiliza de uma outra modalidade de linguagem. (COD119, 1999, p. 42-43).

A visão das pesquisas que destacam a questão da diferença e de classificar a surdez como pertencente à minoria linguística, centra sua análise, principalmente no aspecto linguístico, assim como destaca fatores como identidade, cultura, comunidade, como debates necessários para que a educação de surdos seja compreendida e tenha sua realidade ressignificada por uma visão pautada na alteridade.

Além das concepções pautadas na diferença, tem-se as concepções sustentadas no bilinguismo. Aponto que alguns trabalhos, realizados na década de 90, mencionam o princípio da Integração², vigente na educação especial, na época, na qual a educação das pessoas com deficiência deveria ocorrer de forma gradativa, conforme o grau da deficiência de cada aluno e de sua adaptabilidade ao meio. Na educação de surdos, porém, já sustentam o argumento de uma educação bilíngue, mesmo antes da promulgação da Lei $n^{\circ}$ 10.436/02 e de sua regulamentação por meio do Decreto $n^{\circ} 5626 / 05$, que indica a educação bilíngue. Destaco o excerto abaixo:

2

Segundo Oliveira (2004), o paradigma da integração percebia a pessoa com deficiência como incapaz, como ser que precisava ser reabilitado e adequado à sociedade (modelo médico de deficiência ou modelo clínico-terapêutico). Quanto à questão educacional, o deficiente deveria adentrar gradativamente no ambiente escolar, conforme o seu desempenho e sua sociabilidade. 


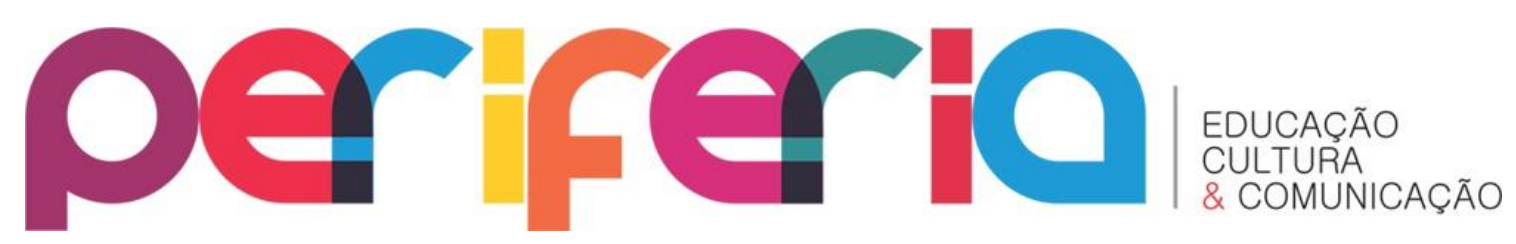

Advogamos, nesse trabalho, a manutenção e a criação de escolas especiais para surdos. Para defender a Integração e a Educação para todos, não apenas como paradigma, mas como possibilidade real na vida cotidiana das pessoas surdas, só nos resta defender a escola especial pelas razões que tem sido aqui explicitadas. $O$ aprendizado de uma língua de modalidade oral só pode acontecer, para os surdos, dentro de uma abordagem educacional diferenciada e por demais específica. Numa abordagem com bilinguismo o processo de ensinoaprendizagem de uma segunda língua de modalidade gestualvisual é uma tarefa que exige metodologias específicas, especiais, que certamente não devem ser as mesmas que dirigem $o$ aprendizado de uma língua materna $e$ de modalidade oral. (COD66, 1996, p. 217).

Como afirmei, essa pesquisa foi anterior as leis da inclusão e, portanto, há nela a defesa clara da escola especial e do bilinguismo, dando destaque para a questão da língua e da relação dos surdos com os seus pares. Assim como a pesquisa indicada, alguns trabalhos defendem uma escola específica para surdos, que busca o distanciamento da visão de deficiência e da educação especial, para aproximar-se de uma visão pautada na diferença.

Com base no Bilinguismo, a escola específica para surdos adquire uma nova dimensão, pois já não se situa no marco da educação especial, que historicamente norteou sua prática, a partir de uma visão reducionista, configurando-se como uma educação de baixa expectativa. Para que a educação bilíngue se desenvolva, era, e ainda é, imprescindível, uma maior profundidade política no trato das questões educacionais do surdo. Nessa direção, a educação bilíngue não pode ser conceitualizada como um novo paradigma na educação especial, mas como um paradigma oposicional. (COD33, 212, p. 105).

A educação bilíngue é apontada como uma oposição à prática desenvolvida ao longo da história pela educação especial, tida como o principal empecilho para o desenvolvimento da educação de surdos, na medida em que poucas expectativas eram traçadas para esses sujeitos. No entanto, tal concepção não se opõe aos determinantes sociais, constituintes 


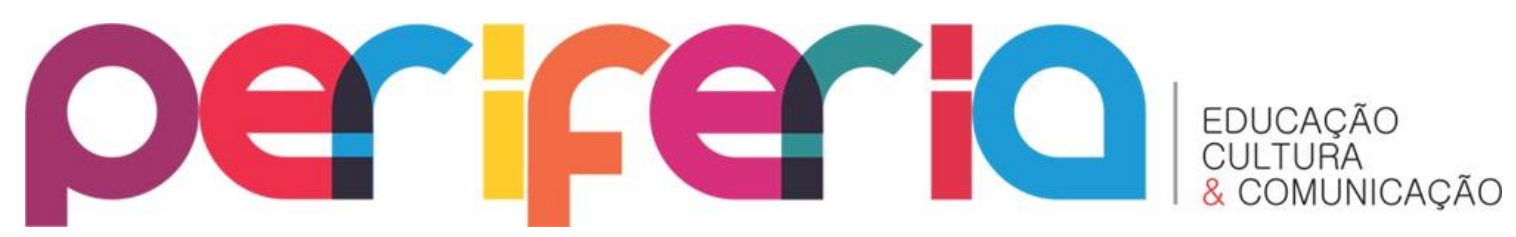

da sociedade capitalista, que se expressa na divisão de classes e nas desigualdades provenientes da exploração através do trabalho.

Outra visão acerca da proposta bilíngue, que corrobora a indicada anteriormente, destaca o aspecto das relações de poder estabelecidas entre surdos e ouvintes, ponderando que essas relações podem ocorrer inclusive em práticas que se intitulam como bilíngues:

\begin{abstract}
A educação bilíngue para a diversidade surda vai além do conhecimento e domínio em algum nível, de duas línguas; se for compreendida dessa forma restritiva, limitada, correrá o risco de transformar-se apenas em um dispositivo pedagógico especial, como destaca Skliar, entendida como uma narrativa educacional utópica. Ainda segundo o autor, "a educação bilíngue numa dimensão política, assume duplo valor: como construção social, cultural e histórica e como relação de poder e conhecimento que delimitam a proposta e o processo educacional". (SKLIAR, 1999, p. 7). (COD185, 2012, p. 45-46).
\end{abstract}

A educação bilíngue é indicada como uma construção histórica, no entanto, no sentido indicado anteriormente por Schaff (1995), na qual a história seria uma relação ascendente dos fatos. A partir dessa visão, a educação do surdo teria saído do calvário do oralismo em direção ao estágio avançado atual, que seria o bilinguismo. Essa visão marca uma concepção restritiva de história e uma percepção limitada dos fatores que determinam a educação de surdos, como limitados às relações de dominação entre surdos e ouvinte, ou entre a ascensão ou declínio da língua de sinais.

Outros trabalhos destacam o bilinguismo ainda como uma proposta a ser implementada, um desejo da comunidade surda, que não acontece ainda na prática, pois essa ainda sofreria as fortes influências do modelo médico.

A educação do surdo é indicada como consequência da visão que se tem sobre ele, das indicadas relações de dominação, na qual o surdo é sempre a vítima. Os trabalhos tem sido marcados por uma sucessiva reprodução de uma visão simplista de educação, pautada no mesmo fator, para explicar a história, a língua, a cultura etc, que seria: a dominação ouvinte sobre o surdo. 


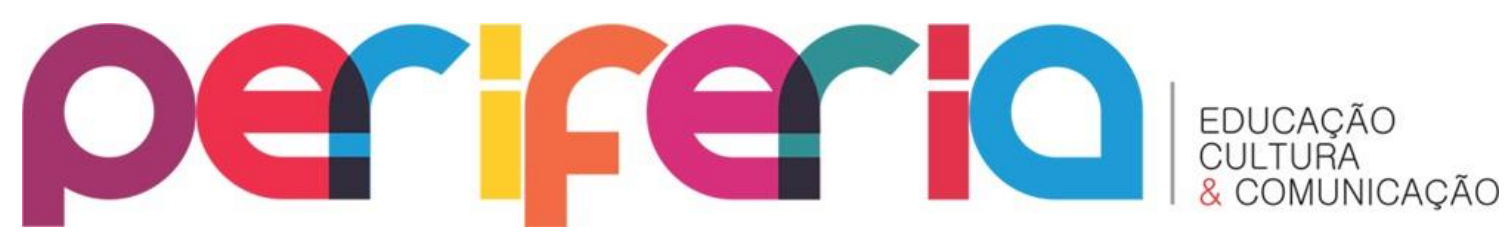

Um dos trabalhos destaca o bilinguismo como forma de desenvolvimento das habilidades linguísticas do surdo, a fim de que possa se apropriar dos conhecimentos científicos veiculados no ambiente escolar.

Em decorrência, a proposta de educação bilíngue atende às necessidades de apropriação de uma língua, de maneira a garantir o aprendizado dos aspectos comunicativos e das formações mentais da criança surda; assim, há a oportunidade de um desenvolvimento de forma plena, já que, nessa concepção, provê também o ensino da língua majoritária oral e, posteriormente, da língua escrita. (COD110, 2010, p. 63).

Poucos são os trabalhos que indicam o argumento da importância da língua para a apropriação dos conhecimentos e destacando a importância da língua para a constituição do gênero humano. A maioria como pode ser observado pelas citações, justifica a importância do bilinguismo e da língua, muito mais como contraposição ao dito ouvintismo e a língua hegemônica, do que como importância linguística para o indivíduo surdo em si e para a apropriação dos conhecimentos.

Precisa haver a valorização de uma concepção que priorize os aspectos culturais, por sua importância no desenvolvimento de uma língua que dê aportes psíquicos que possibilitem a apropriação dos conhecimentos e, a apropriação da língua majoritária, na modalidade escrita, já que é através dela que os conhecimentos são veiculados. Outro trabalho que indica a necessidade de aquisição da língua de sinais, a fim de possibilitar o desenvolvimento cognitivo do surdo, destaca que:

Nesse viés, questões como identidade, cultura e bilinguismo são analisadas com vistas a apontar o lugar que a sociedade, hegemonicamente ouvinte, determina a esses sujeitos e as possibilidades de resistência pela utilização da Libras, língua viso-gestual, como língua materna e natural da comunidade surda. Convém ressaltar que, ao contrário do que o senso comum aponta, os surdos precisam aprender e ser fluentes em língua de sinais para que consigam adquirir os conceitos científicos e se desenvolverem cognitivamente. (GOLDFELD, 2002). (COD182, 2013, p. 19). 


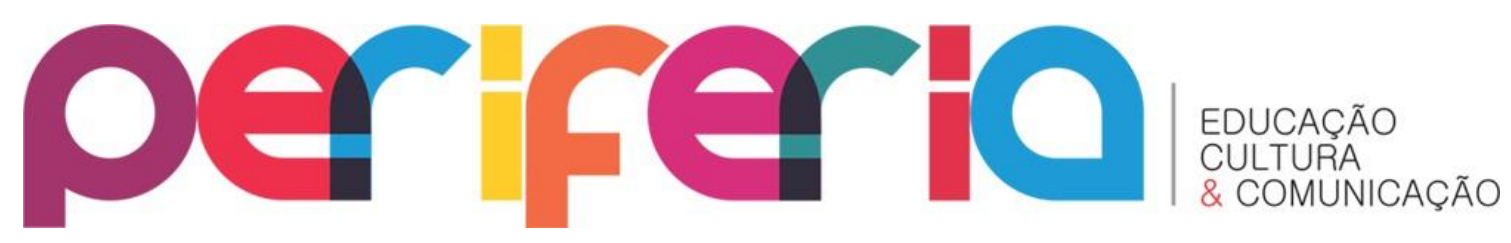

É importante esse destaque dado à necessidade dos surdos aprenderem os conhecimentos científicos, e essa apropriação é possível por meio do domínio da língua escrita, que ao contrário de ser um mecanismo de imposição ouvinte, é um meio cultural constituído historicamente pela objetivação humana, que precisa ser apropriado pelo surdo, para consolidação de sua humanidade.

Outra visão, denominada de Estudos Surdos contrapõe-se com o bilinguismo, visto que não se percebe uma realidade concreta para sua aplicação nas escolas brasileiras. Esses estudos surdos deram aporte teórico para a Pedagogia Surda. Sobre os Estudos Surdos destaco dois excertos de pesquisa diferentes para conceituá-lo;

Os Estudos Surdos, segundo Skliar (2005), problematizam o que não está posto, ou seja, propõem outro olhar sobre o sujeito surdo, em uma tentativa de deslocar a visão puramente clínica do surdo, que marca um corpo deficiente e de sujeitos que necessitam ser "tratados" e "corrigidos". Eles incentivam uma perspectiva que visa a olhar esse sujeito a partir da diferença que se materializa em políticas linguísticas de identidade, comunitárias e culturais. Buscam uma visão planejada e refletida a partir do outro, do próprio surdo, e propõem ter esse sujeito como o eixo dessa circulação. Também promovem a construção de um discurso inspirado por uma base antropológica e cultural. (COD52, 2013, p. 45).

Com a proposta de se contrapor a todas as concepções de educação de surdos e a opressão ouvintista sobre os mesmos, os Estudos Surdos, organizados predominantemente, por pessoas surdas, estudiosas dos aspectos políticos, linguísticos e culturais que envolvem a surdez, traçam várias questões sobre a educação de surdos, dentre as quais a denominada Pedagogia Surda.

Marcada por um forte viés político de demarcação de espaço nos diferentes ambientes sociais para os sujeitos surdos, a chamada Pedagogia Surda, pensada e criada pelos surdos, indica o que seria o mundo surdo e 


\section{periferio}

como seria uma educação sustentada no respeito à sua língua, identidade e cultura. Ela está sendo construída e é proclamada como um meio de resistência e um movimento social em favor da comunidade surda.

A pedagogia surda viria propor como educar os surdos, a partir de determinações deles mesmos, confrontando-se com práticas que denominam ser ouvintistas. As escolas brasileiras têm sido marcadas por uma forte história de segregação, que mais do que ser um embate entre surdos e ouvintes, marca uma luta de classes, na qual os que têm dinheiro tem uma educação de qualidade e os pobres, são deixados à própria sorte, a mercê de uma educação menor.

Todas as concepções destacadas até então, seja o oralismo, comunicação total, bilinguismo ou os Estudos Surdos, tomam como base de debate um confronto entre dois mundos, duas culturas, duas formas de ser, que seria o do surdo versus o do ouvinte. Essa análise restringe o debate da educação de surdos, na medida em que centraliza na surdez e na língua a discussão, o que indica um debate que precisa ser ampliado e vinculado às questões materiais que determinam em última instância, as questões sociais e exercem forte influência no campo educacional.

Bueno e Ferrari (2013) combatem a ideia de a surdez ser o fator determinante da vida, identidade e cultura desses sujeitos, destacando que os aspectos sociais, econômicos, raciais, de sexo, não podem ser desconsiderados ou secundarizados, como tem sido feito nas análises da educação de surdos. A dicotomização entre surdos e ouvintes, que foi criticada pelos autores, está fortemente presente nos trabalhos aqui analisados. Para Bueno e Ferrari (2013, p. 10-11):

considerar a existência de uma "comunidade surda", que abrange somente aqueles surdos que admitem e assumem a "cultura surda" decorrente de uma "apropriação viso-manual" do mundo é desconsiderar, de um lado a existência de um enorme número de surdos que, em razão de condições e trajetórias sociais diferenciadas, utilizam a língua oral como forma básica de comunicação e que pouco ou nada convivem 


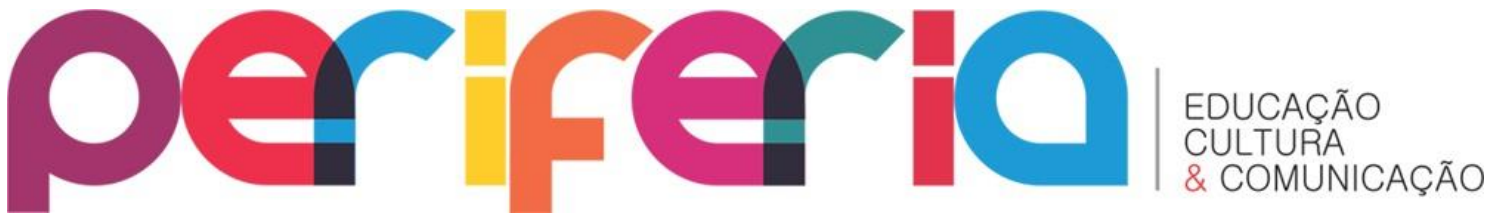

com outros surdos. Considerá-los como não assumindo a sua "identidade surda" é impor uma única possibilidade de socialização, qual seja, a de convívio preferencial com seus "pares".

De outro, é desconsiderar a existência da diversidade das condições sociais e econômicas, da localidade onde vivem, do pertencimento racial, do sexo, da ambiência familiar e da vizinhança, assim como da escolaridade, inserção profissional e trajetória social, ou seja, a centralização de toda a argumentação na apropriação viso-manual dos significados tem como decorrência inquestionável a secundarização de todos esses elementos na constituição das identidades de pessoas surdas. Enfim, a característica fundante, dentro dessa perspectiva, de um indivíduo negro, pobre, mal escolarizado e surdo é a surdez, já que ele se torna, automaticamente, membro da mesma comunidade e partícipe da mesma cultura de um branco, rico, com alto grau de instrução e surdo, porque ambos se caracterizam pela "apropriação visuomanual" dos significados, já que utilizam a língua de sinais.

Os autores são categóricos ao afirmar que essa dicotomização é a causadora e mantenedora da desigualdade social, ao desconsiderar os aspectos sociais, de classe, de raça e de sexo. Tal dicotomização indica a exclusão do surdo como proveniente, exclusivamente, por uma diferença pautada na surdez em si. Tecem seus argumentos, a partir da análise crítica do que eles afirmam ser a imposição da língua de sinais, analisando a Lei $10.436 / 2002$ e o Decreto $n^{\circ} 5626 / 2005$.

Baseados na lei e no decreto criticam a centralidade da língua de sinais, a secundarização da língua portuguesa e a priorização dos sujeitos surdos, nos cursos de formação, em detrimento de pessoas ouvintes. Destacam que essas questões precisam ser analisadas de forma crítica para que não estejam atendendo a uma exclusão do surdo, pois cada vez mais essa dicotomização centra em sua particularidade, deixando de lado os aspectos gerais, tanto sociais quanto educacionais que o determinam.

Para Bueno e Ferrari (2013), o que ocorre na educação de surdos é uma imposição da língua de sinais, uma supervalorização da identidade e cultura surda, apartada da realidade na qual está inserido e uma consequente 


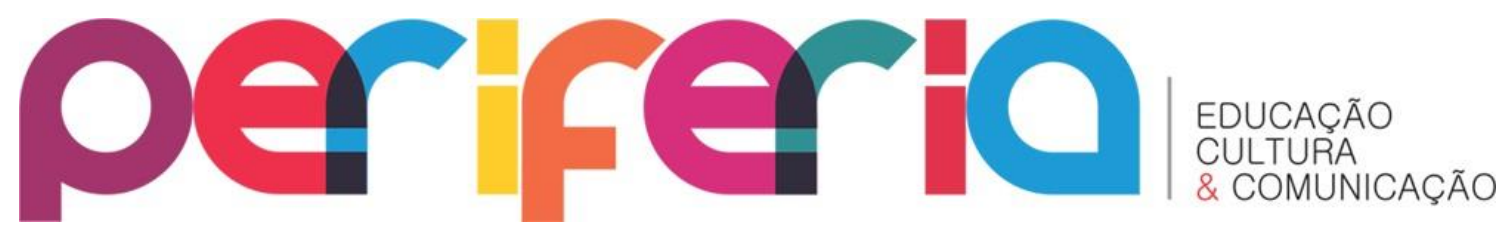

exclusão de quem não se enquadra e se identifica com essas questões. E concluem:

\begin{abstract}
Historicamente, foi sendo construída a concepção de que a oralização de pessoas surdas era uma forma de opressão de uma maioria sobre uma minoria. O tratamento da surdez como uma deficiência não era adequado, pois os caracteriza como doentes que precisavam ser tratados. Ao invés disso, as correntes teóricas e educacionais hegemônicas consideram a surdez como uma diferença e a língua de sinais como a modalidade linguística mais apropriada, por ser constituída viso-manualmente, hegemonia que redundou em legislação que não só reconheceu o direito de alunos surdos serem instruídos por meio da língua de sinais, tal como fez a Lei de Libras, como oficializou a cultura, identidade e língua de sinais como expressão de todo e qualquer surdo, como dispôs o decreto que a regulamentou. (BUENO e FERRARI, 2013, p. 10-11).
\end{abstract}

Os autores são bem enfáticos em indicar que há um predomínio (como também observamos nas pesquisas aqui analisadas) da concepção da surdez como diferença e na centralidade da língua como fatores determinantes para a vida social e educacional desse sujeito.

Analiso o processo histórico de conquistas dos surdos como uma tentativa de demarcar sua posição social e garantir seus direitos de uso da língua de sinais, de acesso ao mercado de trabalho e de direito à educação. Para alcançar esse objetivo, a radicalidade tem se exacerbado e a exclusão, agora dos chamados ouvintes ocorre, como uma tentativa de "vingar" um período indicado por eles como opressão dos ouvintes em relação aos surdos. Embate esse pouco frutífero para atacar os problemas concretos da educação de modo geral.

Bueno (1998) faz alguns questionamentos sobre a denominação de “comunidade surda" e "indivíduos surdos":

Em síntese, será que a surdez é suficiente para identificarmos dois sujeitos como uma mulher, negra, pobre, latinoamericana, vivendo em pequena localidade rural e surda e um homem, branco, rico, norte-americano, vivendo em metrópole 


\section{periferio}

e surdo? Que a surdez é um traço de identificação entre eles não se nega. Mas isto é suficiente para considerá-los como "pares" ou como "iguais"? Eles fazem parte de uma mesma comunidade só pelo fato de serem surdos? (BUENO, 1998, p. 4).

A educação de surdos baseada nos autores marxistas deve buscar argumentos materiais, na realidade concreta da luta de classes para explicar o processo de educação de surdos e de sua in/exclusão.

\section{CONSIDERAÇÕES}

A maioria das pesquisas não questiona essas questões e toma o debate sobre os "Estudos Surdos", a "comunidade surda", "identidade surda", “pedagogia surda” de forma acrítica, baseadas em pesquisadores surdos, levando ao extremo de adotar essas conceituações sem muitas vezes indicar a sustentação epistemológica que norteia tais afirmativas. O chamado "ser surdo" ocupa um lugar privilegiado e até mesmo "sagrado", que não pode ser contestado, estando acima do "bem e do mal", numa visão idealista da surdez, desvinculando-a de qualquer determinante material.

Bueno (1998) critica as apropriações indevidas da teoria multicultural e a confusão do conceito de comunidade e de sociedade, utilizados indistintamente, nos debates sobre a educação de surdos. Enfatiza que:

A meu ver, a forma como se tem trabalhado a questão, em que não são levadas em consideração as formas conflituosas, contraditórias e exploratórias pelas quais a moderna sociedade industrial se constitui, não em relação aos sujeitos ouvintes versus sujeitos surdos, mas envolvendo dominação de classe, de raça e de gênero, redunda em uma visão abstrata da problemática social da surdez e aponta para uma saída idealista: a solução é a criação de comunidades surdas, independentemente das formas como a sociedade em geral se organiza.

Isto é, se o oralismo, tal qual como foi sendo construído historicamente se constitui numa forma opressiva de uma grande maioria sobre uma minoria, o Sinal, visto como redenção do surdo numa sociedade extremamente injusta, 


\section{periferio}

está sendo utilizado como uma outra forma de subjugação, na medida em que encobre outros determinantes fundamentais além da surdez, que jogam peso decisivo na formação de suas identidades e na trajetória de sua autonomia individual. (BUENO, 1998, p. 7-8).

Segundo o autor, o multicultural não pode ser classificado por um único determinante, a partir do qual esse sujeito teria sua cultura e identidades construídas. Em nome da língua, não se deve realizar o mesmo que era feito no oralismo, agora sobre as vestes do bilinguismo, de imposição de uma língua, pois não há uma homogeneidade na adesão e no domínio de tal língua por parte dos surdos.

Não quero afirmar com isso, que a língua de sinais não seja importante, pelo contrário, acredito que o surdo enquanto ser humano tem direito de apropriar-se de uma língua, seja a língua de sinais, seja a língua portuguesa. Por sua condição de não ouvir, quando é surdo de nascença a língua de sinais atenderia melhor a sua necessidade de comunicação, pautada no visual. Mas, não serei categórica, pois o estudo de Vigotski (1983) me fez compreender que o ser humano não pode ser determinado pelo fator biológico e que o seu desenvolvimento psíquico é estabelecido socialmente. Diante de uma adversidade, o cérebro humano, a partir dos estímulos realizados, na sua relação com o mundo e com os outros homens, desenvolve mecanismos de compensação. Assim, as possibilidades de desenvolvimento do gênero humano são infinitas. Essa questão será apresentada de forma mais detalhada na seção seguinte.

A apropriação de uma língua, além de ser uma forma de o sujeito objetivar-se enquanto gênero humano, é importante, a fim de permitir-lhe compreender a sua história e a realidade da sociedade de classes e a exclusão dela proveniente, que está entranhada no modelo capitalista de produção. Dessa forma, a língua é importante, no entanto, o que irá determinar o desenvolvimento da individualidade e da educação de um ser humano, são fatores externos. 


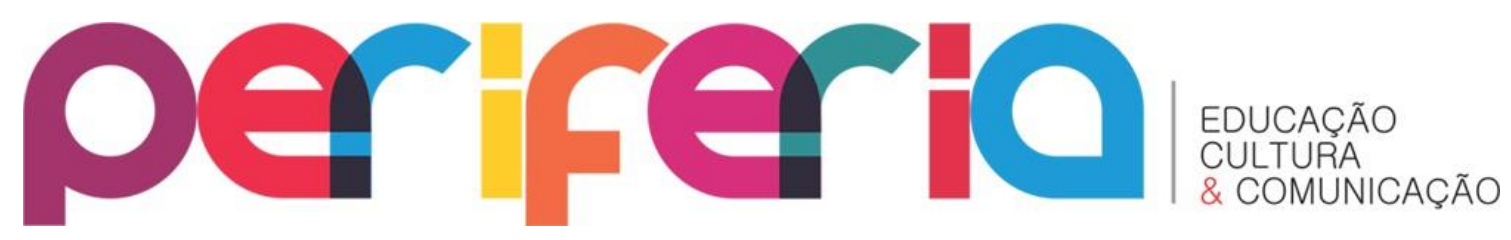

A análise predominante nas pesquisas aqui tomadas como dados empíricos, a partir da qual compreende que o debate em torno da educação dos surdos, é proveniente do combate a uma visão ouvintista. A determinação da educação do surdo e sua classificação como possuindo uma determinada identidade e como pertencente à uma cultura, tendo como base um único indicador, a surdez, são contraditórias com o debate da psicologia históricocultural proposta por Vigotski (1983). Essas visões particularizadas distanciam a educação dos surdos dos reais problemas que assolam não só uma parcela desses sujeitos (os pobres) como a classe trabalhadora.

\section{REFERENCIAS}

BRASIL. Lei $n^{\circ}$ 10.436, de 24 de abril de 2002. Brasília, 24 de abril de 2002; $181^{\circ}$ da Independência e $114^{\circ}$ da República.

. Secretaria de Educação Especial. Decreto 5.626, de 22 de dezembro de 2005. (LIBRAS). Brasília, 2005

BUENO, José Geraldo Silveira; FERRARI, Carla Cazelato Ceará. Contrapontos sócio-educacionais da surdez: para além da marca da deficiência. In: CEARÁ. ASSEMBLÉIA LEGISLATIVA. Cadernos Tramas da Memória. Fortaleza, Memorial da Assembléia Legislativa do Ceará - MALCE, 2013. (no prelo).

BUENO, José Geraldo Silveira. Surdez, linguagem e cultura. Caderno CEDES, Campinas-SP, n.46, p.41-54, 1998.

. Educação Especial Brasileira: questões conceituais e da atualidade.

São Paulo: EDUC, 2011.

SCHAFF, Adam. História e Verdade. Tradução Maria Paula Duarte; revisão Carlos Roberto F. Nogueira. 6ed. São Paulo: Martins Fontes, 1995. (Ensino Superior).

SILVA, Ângela Carrancho da. Surdez, educação de surdos e sociedade. In: SILVA, Ângela Carrancho da; NEMBRI, Armando Guimarães. Ouvindo o Silêncio: surdez, linguagem e educação. Porto Alegre: Mediação, 2008. p.17-56.

VYGOTSKI, L.S. Obras Escogidas V. Fundamentos de defectología. Moscú: Editorial Pedagógica, 1983. 